Check for updates

Cite this: RSC Adv., 2018, 8, 36903

Received 18th September 2018 Accepted 17th October 2018

DOI: $10.1039 / c 8 r a 07749 e$

rsc.li/rsc-advances

\title{
One step synthesis of high-efficiency $\mathrm{AgBr}-\mathrm{Br}-\mathrm{g}-$
$\mathrm{C}_{3} \mathrm{~N}_{4}$ composite catalysts for photocatalytic $\mathrm{H}_{2} \mathrm{O}_{2}$ \\ One step synthesis of high-efficiency $\mathrm{AgBr}-\mathrm{Br}-\mathrm{g}-$
$\mathrm{C}_{3} \mathrm{~N}_{4}$ composite catalysts for photocatalytic $\mathrm{H}_{2} \mathrm{O}_{2}$ production via two channel pathway
}

\author{
Yunke Wang, Shaozheng Hu, Qiang Li, Guizhou Gu, Yanfeng Zhao, Hongyu Liang \\ and Wei Li (D)*
}

In this work, a two-component modified $\mathrm{AgBr}-\mathrm{Br}-\mathrm{g}-\mathrm{C}_{3} \mathrm{~N}_{4}$ composite catalyst with outstanding photocatalytic $\mathrm{H}_{2} \mathrm{O}_{2}$ production ability is synthesized. XRD, UV-Vis, $\mathrm{N}_{2}$ adsorption, TEM, XPS, EPR and PL were used to characterize the obtained catalysts. The as-prepared $\mathrm{AgBr}-\mathrm{Br}-\mathrm{g}-\mathrm{C}_{3} \mathrm{~N}_{4}$ composite catalyst shows the highest $\mathrm{H}_{2} \mathrm{O}_{2}$ equilibrium concentration of $3.9 \mathrm{mmol} \mathrm{L}^{-1}$, which is 7.8 and 19.5 times higher than that of GCN and AgBr. A "two channel pathway" is proposed for this reaction system which causes the remarkably promoted $\mathrm{H}_{2} \mathrm{O}_{2}$ production ability. In addition, compared with another two-component modified catalyst, $\mathrm{Ag}-\mathrm{AgBr}-\mathrm{g}-\mathrm{C}_{3} \mathrm{~N}_{4}, \mathrm{AgBr}-\mathrm{Br}-\mathrm{g}-\mathrm{C}_{3} \mathrm{~N}_{4}$ composite catalyst displays the higher photocatalytic $\mathrm{H}_{2} \mathrm{O}_{2}$ production ability and stability.

\section{Introduction}

Hydrogen peroxide $\left(\mathrm{H}_{2} \mathrm{O}_{2}\right)$ is a highly efficient and green oxidant because it has a high content of active oxygen $(47 \% \mathrm{w} / \mathrm{w})$ and results in only $\mathrm{H}_{2} \mathrm{O}$ as a by-product. ${ }^{\mathbf{1 , 2}}$ Industrially, $\mathrm{H}_{2} \mathrm{O}_{2}$ is produced by the anthraquinone method, in which energy consumption is high because of the multistep hydrogenation and oxidation reactions. Thus this method is unsuitable for the current new concept of being "green, energy saving, and environmentally friendly" in the chemical industry. Recently, the direct synthesis of $\mathrm{H}_{2} \mathrm{O}_{2}$ from $\mathrm{H}_{2}$ and $\mathrm{O}_{2}$ gases has been widely studied using noble metals as catalysts. ${ }^{3,4}$ It is considered to be an alternative and green chemical process. However, this method presents a potential explosion risk from $\mathrm{H}_{2} / \mathrm{O}_{2}$ mixtures. In contrast, photocatalytic $\mathrm{H}_{2} \mathrm{O}_{2}$ production requires only water, oxygen and visible light through two-electron reduction from the conduction band (reaction (1)). However, the $\mathrm{H}_{2} \mathrm{O}_{2}$ can be decomposed by reduction with $\mathrm{e}^{-}$, which has caused the $\mathrm{H}_{2} \mathrm{O}_{2}$ production rate of this photocatalytic reduction method to be unsatisfactory to date (reaction (2)).

$$
\begin{gathered}
\mathrm{O}_{2}+2 \mathrm{H}^{+}+2 \mathrm{e}^{-} \rightarrow \mathrm{H}_{2} \mathrm{O}_{2} \\
\mathrm{H}_{2} \mathrm{O}_{2}+\mathrm{e}^{-} \rightarrow \cdot \mathrm{OH}+\mathrm{OH}^{-}
\end{gathered}
$$

Graphite phase carbon nitride $\left(\mathrm{g}-\mathrm{C}_{3} \mathrm{~N}_{4}\right)$, as the darling of the catalytic community in recent years, has special physical and chemical properties, excellent chemical stability and adjustable electronic structure., 5 since its conduction band potential

College of Chemistry, Chemical Engineering, and Environmental Engineering, Liaoning Shihua University, Fushun 113001, China.E-mail: weililnpu@163.com
$(-1.3 \mathrm{~V})$ is more negative than the reduction potential of $\mathrm{O}_{2} /$ $\mathrm{H}_{2} \mathrm{O}_{2}(0.695 \mathrm{~V}), \mathrm{g}-\mathrm{C}_{3} \mathrm{~N}_{4}$ could reduce $\mathrm{O}_{2}$ to $\mathrm{H}_{2} \mathrm{O}_{2}$ under visible light thermodynamically. ${ }^{7}$ However, $g-\mathrm{C}_{3} \mathrm{~N}_{4}$ also suffers from many disadvantages, such as the low visible-light utilization efficiency, high recombination rate and small BET surface area, which limit its practical application.

$\operatorname{AgX}(\mathrm{X}=\mathrm{Cl}, \mathrm{Br}, \mathrm{I})$ is a kind of common photocatalyst. They have the moderate energy level which is very appropriate to combine with $\mathrm{g}-\mathrm{C}_{3} \mathrm{~N}_{4}$ for building heterojunction to resolve these disadvantages mentioned above. ${ }^{8-14}$ Feng et al. prepared g$\mathrm{C}_{3} \mathrm{~N}_{4} / \mathrm{AgBr}$ nanocomposite photocatalyst via a protonation pretreatment method. ${ }^{8}$ They found the efficient combination of g- $\mathrm{C}_{3} \mathrm{~N}_{4}$ and $\mathrm{AgBr}$ leads to $Z$-scheme charge transfer in the composite system, and the photocatalytic activity is therefore enhanced significantly. Liu et al. prepared AgI@g- $\mathrm{C}_{3} \mathrm{~N}_{4}$ hybrid core@shell structure by ultrasonication/chemisorption method. ${ }^{9}$ They suggested that the improved photocatalytic performance is due to synergistic effects at the interface of AgI and $\mathrm{g}-\mathrm{C}_{3} \mathrm{~N}_{4}$ which can effectively accelerate the charge separation and reinforce the photostability of hybrid composite. In addition of building heterojunction with silver halide, halogen doping and Ag loading are also efficient method to promote the visible-light utilization efficiency and separation rate of electrons-holes. Lan et al. prepared $\mathrm{Br}$ doped $\mathrm{g}-\mathrm{C}_{3} \mathrm{~N}_{4}$ for photoredox water splitting via one-pot co-condensation of urea with $\mathrm{NH}_{4} \mathrm{Br}^{15}$ The optimal sample shows more than two times higher $\mathrm{H}_{2}$ evolution rates than pure $\mathrm{g}-\mathrm{C}_{3} \mathrm{~N}_{4}$ under visible light irradiation, with high stability during the prolonged photocatalytic operation. Bu et al. prepared $\mathrm{Ag}$ loaded mesoporous g$\mathrm{C}_{3} \mathrm{~N}_{4}$ with high photoelectric conversion performance. ${ }^{16}$ They suggested that modifying mesoporous $\mathrm{g}-\mathrm{C}_{3} \mathrm{~N}_{4}$ with $\mathrm{Ag}$ increases the conductivity and lowers the energy barrier of the interface 
reactions, thus enhances the separation efficiency of photogenerated electron-hole pairs.

Besides, two-component modification, such as Ag-AgX, are also used to promote the catalytic performance of $\mathrm{g}-\mathrm{C}_{3} \mathrm{~N}_{4} \cdot{ }^{17,18}$ Wang et al. prepared a high-efficiency g- $_{3} \mathrm{~N}_{4} / \mathrm{Ag} / \mathrm{AgCl}$ plasmonic photocatalyst via a facile solvothermal method. ${ }^{17}$ The surface plasmon resonance effect of the $\mathrm{Ag}$ nanoparticles, the polarization field of $\mathrm{AgCl}$ and the $\mathrm{g}-\mathrm{C}_{3} \mathrm{~N}_{4} / \mathrm{Ag} / \mathrm{AgCl}$ heterojunction all result in the improved photocatalytic degradation performance. Chen et al. prepared plasmonic photocatalyst $\mathrm{Ag} /$ $\mathrm{AgBr} / \mathrm{g}-\mathrm{C}_{3} \mathrm{~N}_{4}$ by in situ ionic-liquid-assisted synthesis. ${ }^{18}$ The enhanced photocatalytic activity is assigned to the extended light-absorption range and efficient charge separation caused by the surface plasmon resonance effect of $\mathrm{Ag}^{0}$ and the wellmatched overlapping band-structure between $\mathrm{Ag} / \mathrm{AgBr}$ and $\mathrm{g}$ $\mathrm{C}_{3} \mathrm{~N}_{4}$. Interestingly, till now, few literature concerning silver halide-halogen-g- $\mathrm{C}_{3} \mathrm{~N}_{4}$ catalyst is reported. $\mathrm{F}$ and I have been applied to dope $\mathrm{g}-\mathrm{C}_{3} \mathrm{~N}_{4}$. It was found that $\mathrm{F}$ dopant give much less promotional effect on the optical absorption of $\mathrm{g}-\mathrm{C}_{3} \mathrm{~N}_{4}$ than I. ${ }^{19}$ This is because the valence electrons in I atom with much less electronegativity are more delocalized to interact with the $\pi$ electron system of $\mathrm{g}-\mathrm{C}_{3} \mathrm{~N}_{4}$. Such an extended conjugation system gives rise to the red-shift of the optical absorption of g$\mathrm{C}_{3} \mathrm{~N}_{4}$. However, the overlarge size of I atom is thermodynamically and geometrically difficult to dope into $\mathrm{g}_{-} \mathrm{C}_{3} \mathrm{~N}_{4}$ to form stable structure. To this end, $\mathrm{Br}$ in the middle of $\mathrm{F}$ and $\mathrm{I}$ is a recommended choice to modify g- $\mathrm{C}_{3} \mathrm{~N}_{4}$. In this work, $\mathrm{AgBr}-$ $\mathrm{Br}-\mathrm{g}-\mathrm{C}_{3} \mathrm{~N}_{4}$ composite catalyst is prepared via one-pot synthesis. The as-prepared $\mathrm{AgBr}-\mathrm{Br}-\mathrm{g}-\mathrm{C}_{3} \mathrm{~N}_{4}$ composite catalyst is applied for photocatalytic $\mathrm{H}_{2} \mathrm{O}_{2}$ production under visible light irradiation. The effects of modification on the structural property, optical property, and photocatalytic performance of catalysts are discussed in detail. The possible reaction mechanism is proposed.

\section{Experimental}

\section{Preparation and characterization}

$4 \mathrm{~g}$ of dicyandiamide and desired amount of $\mathrm{AgNO}_{3}$ were dissolved into $40 \mathrm{~mL}$ deionized water under stirring to obtain solution A. Then, $\mathrm{NH}_{4} \mathrm{Br}$ solution was added dropwise into solution $\mathrm{A}$ (molar ratio $\mathrm{Ag} / \mathrm{Br}=1$ ). The obtained suspension was stirred for $2 \mathrm{~h}$, and heated to $80{ }^{\circ} \mathrm{C}$ to remove the water. The solid was dried at $80^{\circ} \mathrm{C}$ and followed by milling and annealing at $550{ }^{\circ} \mathrm{C}$ for $2 \mathrm{~h}$ (at a rate of $5{ }^{\circ} \mathrm{C} \mathrm{min}^{-1}$ ). The obtained catalyst was denoted as $\mathrm{AgBr} / \mathrm{GCN}(x)$, where $x$ stands for the mass ratio of $\mathrm{AgBr} /$ dicyandiamide. Neat $\mathrm{AgBr}$ was prepared according to the method mentioned above in the absence of dicyandiamide. When excess $\mathrm{NH}_{4} \mathrm{Br}$ was added into solution $\mathrm{A}$ and followed the same procedure mentioned above, the prepared catalyst was denoted as $\operatorname{Ag} \operatorname{Br} / \operatorname{Br}(y)-\operatorname{GCN}(x)$, where $y$ stands for the molar ratio of $\mathrm{Ag} / \mathrm{Br}$.

The XRD patterns of the samples were recorded on a Rigaku $\mathrm{D} /$ max-2400 instrument using Cu-K $\alpha$ radiation $(\lambda=1.54 \AA)$. UVVis spectroscopy was carried out on a UV-Vis spectrophotometer (JASCO V-550) using $\mathrm{BaSO}_{4}$ as the reflectance sample. TEM images were taken on a Philips Tecnai G220 model microscope.
Nitrogen adsorption was measured at $-196{ }^{\circ} \mathrm{C}$ on a Micromeritics 2010 analyzer. The BET surface area $\left(S_{\mathrm{BET}}\right)$ was calculated based on the adsorption isotherm. Elemental analysis was performed using a vario EL cube from Elementar Analysensysteme GmbH. ICP was performed on a Perkin-Elmer Optima 3300DV apparatus. The XPS results were obtained on a Thermo Escalab 250 XPS system. Al $\mathrm{K} \alpha$ radiation was used as the excitation source. The electron paramagnetic resonance (EPR) was determined with a Bruker ESR 300E, using the radical scavenger dimethyl pyridine N-oxide (DMPO). The photoluminescence (PL) spectra were measured with a fluorospectrophotometer (FP-6300) using Xe lamp as the excitation source.

\section{Photocatalytic reaction}

The photocatalytic $\mathrm{H}_{2} \mathrm{O}_{2}$ production ability of the samples was evaluated by the reduction of molecular oxygen. For these experiments, $0.2 \mathrm{~g}$ of photocatalyst was added to $200 \mathrm{~mL}$ of deionized water. The suspension was dispersed using an ultrasonicator for $10 \mathrm{~min}$. During the photoreaction under visible light irradiation, the suspension was exposed to a $250 \mathrm{~W}$ high-pressure sodium lamp with main emission from 400 to $800 \mathrm{~nm}$, and $\mathrm{O}_{2}$ was bubbled at $80 \mathrm{~mL} \mathrm{~min}{ }^{-1}$ through the solution. The UV light portion of the sodium lamp was filtered by a $0.5 \mathrm{M} \mathrm{NaNO}_{2}$ solution. All runs were conducted at ambient pressure and $30{ }^{\circ} \mathrm{C}$. At given time intervals, $5 \mathrm{~mL}$ aliquots of the suspension were collected and immediately centrifuged to separate the liquid samples from the solid catalyst. The $\mathrm{H}_{2} \mathrm{O}_{2}$ concentration was analyzed by the normal iodometric method. ${ }^{20,21}$

\section{Results and discussion}

Fig. 1 shows the XRD patterns of GCN, AgBr and as-prepared composite catalysts. The characteristic peak of GCN around $27.5^{\circ}$ could be clearly identified, which is attributed to the typical $\left(\begin{array}{lll}0 & 0 & 2\end{array}\right)$ interlayer-stacking peak corresponds to an interlayer distance of $d=0.33 \mathrm{~nm}$. The peak at $13.1^{\circ}$ represents in-plane structural packing motif with a $d$ value of $0.675 \mathrm{~nm} .{ }^{22}$ For $\mathrm{AgBr}$, the sample shows several diffraction peaks at $31.0^{\circ}$,

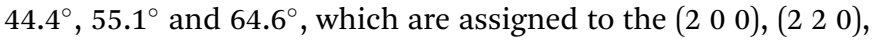
( $\left.\begin{array}{lll}2 & 2 & 2\end{array}\right)$ and (4 00 ) planes of AgBr crystal (JCPDS file: 6-438). ${ }^{8,18}$ In the case of as-prepared composite catalysts, the peak position does not shift but the intensity for AgBr (GCN) decreases (increases) gradually with increasing the amount of GCN, as shown in Fig. 1a. It is shown in Fig. 1b that, when excess Br was
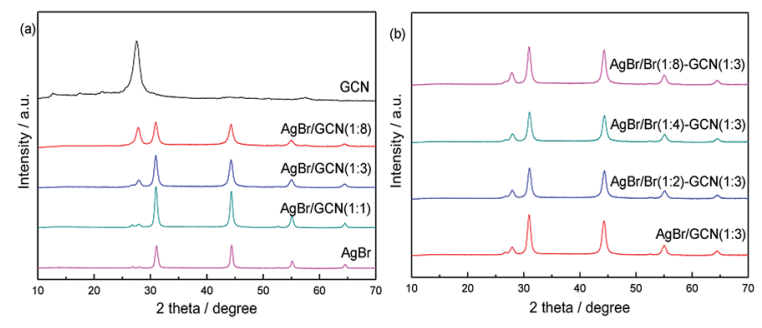

Fig. 1 XRD patterns of as-prepared catalysts. 
added, the peak intensity and position for both GCN and $\mathrm{AgBr}$ are not changed. In addition, the element analysis and ICP results indicate that, the $\mathrm{AgBr}$ concentrations in $\mathrm{AgBr} /$ $\operatorname{GCN}(1: 8), \operatorname{AgBr} / \mathrm{GCN}(1: 3)$ and $\operatorname{AgBr} / \mathrm{GCN}(1: 1)$ are $26 \mathrm{wt} \%$, $42 \mathrm{wt} \%$ and $69 \mathrm{wt} \%$, respectively. For $\operatorname{AgBr} / \operatorname{Br}(1: 2)-\mathrm{GCN}(1: 3)$, $\operatorname{AgBr} / \operatorname{Br}(1: 4)-\mathrm{GCN}(1: 3)$ and $\operatorname{AgBr} / \operatorname{Br}(1: 8)-\mathrm{GCN}(1: 3)$, the doping $\mathrm{Br}$ concentrations are $0.25 \mathrm{wt} \%, 0.44 \mathrm{wt} \%$ and $0.72 \mathrm{wt} \%$, respectively.

Fig. 2a displays the UV-Vis spectra of as-prepared catalysts. GCN shows the typical absorption spectrum of graphitic carbon nitride semiconductor with an absorption boundary at approximately $450 \mathrm{~nm}$. For $\mathrm{AgBr}$, the absorption in the whole region is stronger than that of GCN. Its absorption boundary is around $490 \mathrm{~nm}$. In the case of as-prepared composite catalysts, compared with GCN, their absorption boundaries are shifted slightly to 460-470 $\mathrm{nm}$. The higher Br/Ag molar ratio, the larger shift of absorption boundary. In addition, because of the presence of $\mathrm{AgBr}$, the composite catalysts display the increased absorption in the whole visible light region. The band gaps of samples were calculated according to the method of Oregan and Gratzel. ${ }^{23}$ The result shows that the band gap for GCN, AgBr/ $\operatorname{Br}(1: 2)-G C N(1: 3), \operatorname{AgBr} / \operatorname{Br}(1: 4)-G C N(1: 3), \operatorname{AgBr} / \operatorname{Br}(1: 8)-$ $\mathrm{GCN}(1: 3)$ and $\mathrm{AgBr}$ is 2.75, 2.69, 2.65, 2.63 and $2.53 \mathrm{eV}$, respectively. This indicates that Br doping influence the energy band position of as-prepared catalysts. Fig. $2 \mathrm{~b}$ displays the $\mathrm{N}_{2}$ adsorption-desorption isotherms of as-prepared catalysts. All the catalysts exhibit type IV isotherm. The specific surface area $\left(S_{\mathrm{BET}}\right)$ of GCN, AgBr and AgBr/GCN(1:3), calculated by the BET method, are 9.5, 13.2 and $10.9 \mathrm{~m}^{2} \mathrm{~g}^{-1}$, respectively. In the case of $\mathrm{AgBr} / \mathrm{Br}(1: 4)-\mathrm{GCN}(1: 3)$, its $S_{\mathrm{BET}}$ is $11.4 \mathrm{~m}^{2} \mathrm{~g}^{-1}$, very close to that of $\mathrm{AgBr} / \mathrm{GCN}(1: 3)$. This hints $\mathrm{Br}$ doping does not influence the $S_{\mathrm{BET}}$ of catalyst.

The morphologies of the representative samples were examined by TEM analysis. As shown in Fig. 3a, GCN shows sheet-like structure with no regular morphology. The morphology for $\mathrm{AgBr}$ is nanorod, as shown in Fig. $3 \mathrm{~b}$. In the case of $\operatorname{AgBr} / \operatorname{Br}(1: 4)-\mathrm{GCN}(1: 3)$ (Fig. 3c), both plate-like structural GCN and $\mathrm{AgBr}$ nanorod are observed, confirming the presence of both $\mathrm{GCN}$ and $\mathrm{AgBr}$. The two-dimensional ordering of GCN is very weak and hard to find the lattice fringe in HRTEM image (Fig. 3d). This is consistent with previous work. ${ }^{18}$ However, the clear lattice fringe is observed for $\mathrm{AgBr}$, very close to the (400) crystal face with the $d=0.143 \mathrm{~nm}$ (Fig. 3d). This tight coupling is favorable for the charge transfer between GCN and $\mathrm{AgBr}$ and promotes the separation rate of electron-hole pairs.
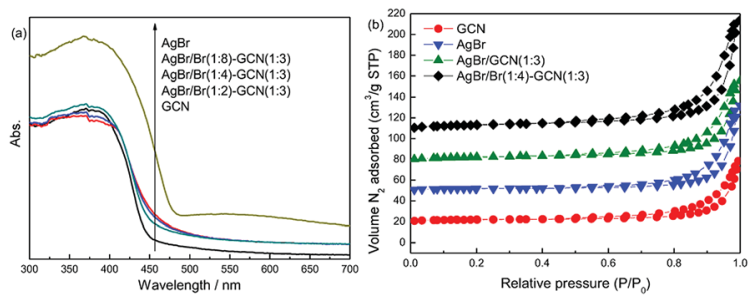

Fig. 2 UV-Vis (a) and $\mathrm{N}_{2}$ adsorption-desorption isotherms (b) of asprepared catalysts.

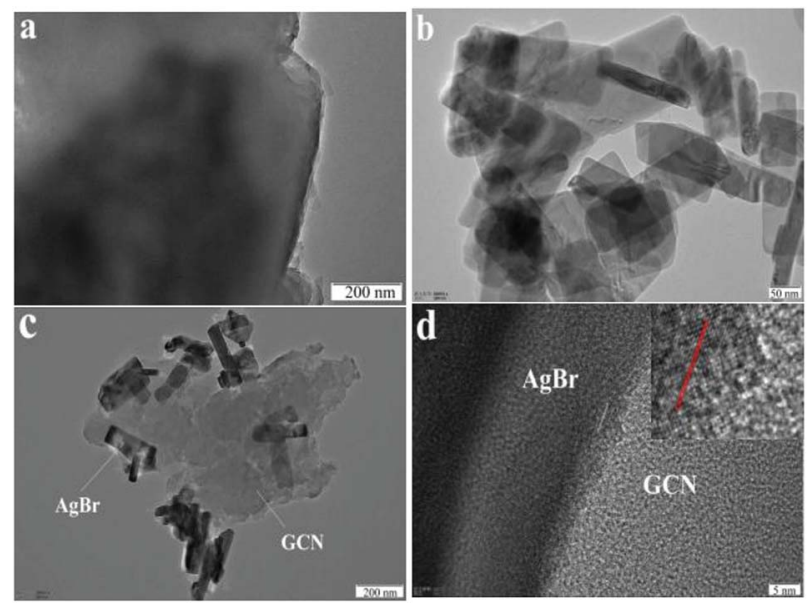

Fig. 3 TEM images of GCN (a), $\operatorname{AgBr}(b)$ and $\operatorname{AgBr} / \operatorname{Br}(1: 4)-G C N(1: 3)$ (c and d).

XPS spectra are used to investigate the structure of the asprepared catalysts. In Fig. 4a, the spectra of three catalysts in $\mathrm{C}$ 1s region can be fitted with two contributions which located at 284.6 and $288.6 \mathrm{eV}$. The sharp peak around $284.6 \mathrm{eV}$ is attributed to the pure graphitic species in the $\mathrm{CN}$ matrix. The peak with binding energy of $288.6 \mathrm{eV}$ indicates the presence of $\mathrm{sp}^{2} \mathrm{C}$ atoms bonded to aliphatic amine $\left(-\mathrm{NH}_{2}\right.$ or $\left.-\mathrm{NH}-\right)$ in the aromatic rings. ${ }^{24-26}$ For $\mathrm{N}$ 1s region (Fig. $4 \mathrm{~b}$ ), three contributions located at 398.3, 399 and $400.5 \mathrm{eV}$ were assigned to the $\mathrm{sp}^{2}$ hybridized aromatic nitrogen atoms bonded to carbon atoms $(\mathrm{C}-\mathrm{N}=\mathrm{C})$, tertiary nitrogen $\mathrm{N}-(\mathrm{C})_{3}$ groups linking structural
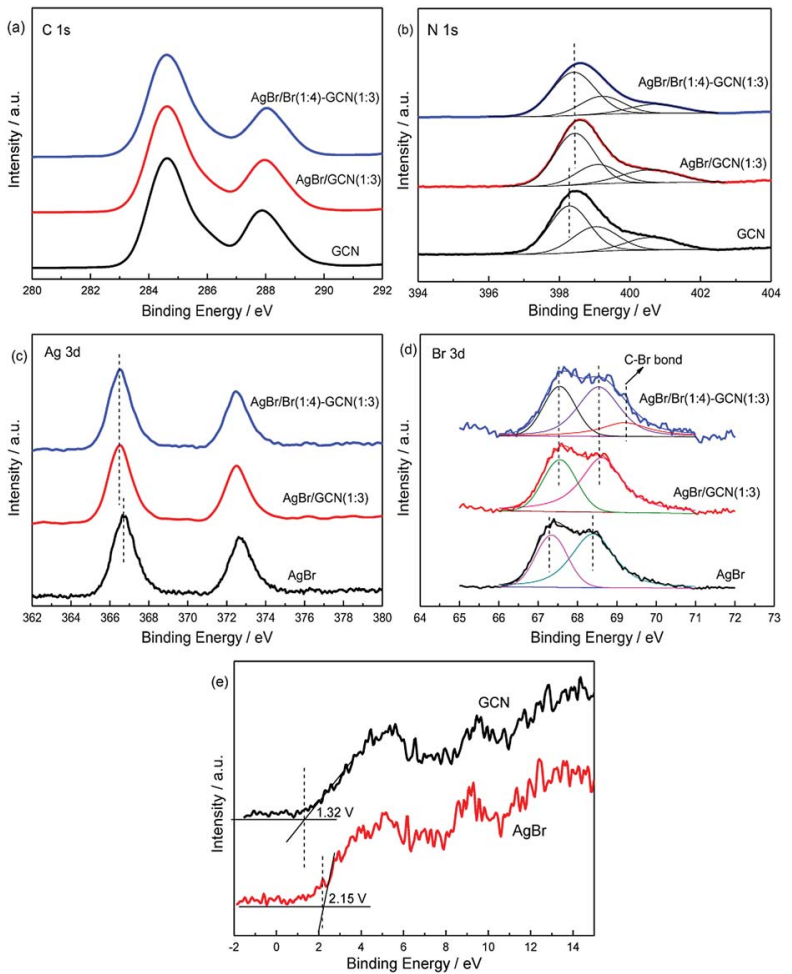

Fig. 4 XPS of as-prepared catalysts in the C 1s (a), N 1s (b), Ag 3d (c), Br $3 d(d)$ and VB XPS (e) regions. 
motif or amino groups carrying hydrogen $\left((\mathrm{C})_{2}-\mathrm{N}-\mathrm{H}\right)$ in connection with structural defects and incomplete condensation, and nitrogen atoms bonded three carbon atoms in the aromatic cycles. ${ }^{27,28}$ For $\operatorname{AgBr} / \mathrm{GCN}(1: 3)$ and $\operatorname{AgBr} / \operatorname{Br}(1: 4)-$ $\operatorname{GCN}(1: 3)$, the obvious shifts to higher binding energies are observed in N 1s region compared with that of neat GCN. This is probably due to the change of chemical environment after coupling with AgBr.

In Fig. 4c, AgBr displays Ag 3d spectrum with two peaks at $366.8 \mathrm{eV}$ and $372.8 \mathrm{eV}$, corresponding to the binding energies of $\mathrm{Ag} 3 \mathrm{~d}_{5 / 2}$ and $\mathrm{Ag} 3 \mathrm{~d}_{3 / 2}$ of $\mathrm{Ag}^{+}$in $\mathrm{AgBr}$, respectively. ${ }^{29}$ In $\mathrm{Br} 3 \mathrm{~d}$ region (Fig. 4d), the peaks at $\sim 67.5$ and $68.3 \mathrm{eV}$ for $\mathrm{AgBr}$ are assigned to the $\mathrm{Br} 3 \mathrm{~d}_{5 / 2}$ and $\mathrm{Br} 3 \mathrm{~d}_{3 / 2}$ of $\mathrm{Br}^{-}$state. ${ }^{30}$ For $\mathrm{AgBr} /$ $\operatorname{GCN}(1: 3)$, the binding energies shift obviously in both $\mathrm{Ag} 3 \mathrm{~d}$ and $\mathrm{Br} 3 \mathrm{~d}$ regions compared with neat $\mathrm{AgBr}$, which confirms the strong interaction between $\mathrm{AgBr}$ and $\mathrm{GCN}$. $\operatorname{AgBr} / \operatorname{Br}(1: 4)$ $\operatorname{GCN}(1: 3)$ displays the same peak position with $\mathrm{AgBr} /$ $\mathrm{GCN}(1: 3)$ in both $\mathrm{Ag} 3 \mathrm{~d}$ and $\mathrm{Br} 3 \mathrm{~d}$ regions. Moreover, a new peak at $69.4 \mathrm{eV}$ is observed for $\operatorname{AgBr} / \operatorname{Br}(1: 4)-\mathrm{GCN}(1: 3)$. This binding energy should be assigned to the $\mathrm{C}-\mathrm{Br}$ bond, which confirming that $\mathrm{Br}$ is doped into $\mathrm{g}-\mathrm{C}_{3} \mathrm{~N}_{4}$ lattice. ${ }^{31}$ The VB XPS spectra were employed to determine the electronic structure (Fig. 4e). It is obvious to see that the VB potentials for GCN and AgBr locate at +1.32 and $+2.15 \mathrm{~V}$. They are very close to the previous results.,18 Combined with the UV-Vis results, the energy position of $\mathrm{CB}$ for GCN and AgBr locate at -1.43 and $-0.38 \mathrm{~V}$ respectively. Obviously, the band structures of the two components are well-matched with each other. This facilitates the formation of heterojunction for charge transfer.

Fig. 5 shows the PL spectra of as-prepared catalysts under air atmosphere using excitation at $255 \mathrm{~nm}$. For GCN (Fig. 5a), broad PL band around $460 \mathrm{~nm}$ is observed with the energy of light approximately equal to the band gap of $\mathrm{g}-\mathrm{C}_{3} \mathrm{~N}_{4}$. AgBr exhibits several emission peaks which intensities are higher than that of GCN. In the case of as-prepared heterojunction catalysts, the PL spectra show the similar shape to that of GCN, whereas the intensities are obviously decreased. $\operatorname{AgBr} / \operatorname{GCN}(1: 3)$ shows the lowest PL intensity, hinting its most effective separation rate of electrons and holes. This is reasonable because, with this GCN/ $\mathrm{AgBr}$ mass ratio, GCN and $\mathrm{AgBr}$ have the approximate $S_{\mathrm{BET}}(9.5$ and $13.2 \mathrm{~m}^{2} \mathrm{~g}^{-1}$ for GCN and $\mathrm{AgBr}$, the yield for GCN is approximately $50 \mathrm{wt} \%$ ). They can contact with each other as much as possible, leading to the formation of the maximum area of the heterojunction.

In Fig. 5b, it is shown that, compared with $\operatorname{AgBr} / \operatorname{GCN}(1: 3)$, the PL intensity is sharply decreased for $\operatorname{AgBr} / \operatorname{Br}(1: 2)$ -
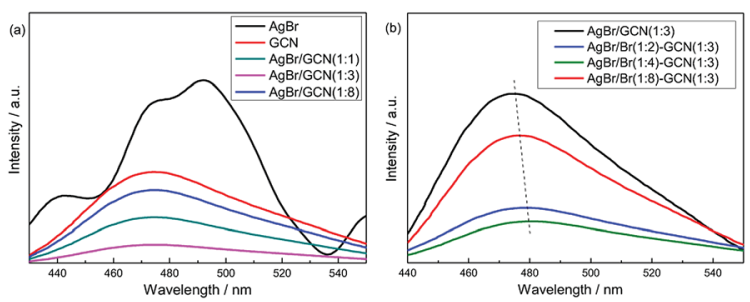

Fig. $5 \mathrm{PL}$ spectra of as-prepared catalysts.
$\operatorname{GCN}(1: 3)$ and $\operatorname{AgBr} / \operatorname{Br}(1: 4)-\operatorname{GCN}(1: 3)$, accompanying with the obvious red-shift. This is probably due to that the doping $\mathrm{Br}$ atoms can induce strong spin-orbit interaction in GCN and result in the conversion of singlet-excited GCN into tripletexcited GCN. For $\operatorname{AgBr} / \operatorname{Br}(1: 8)-G C N(1: 3)$, its PL intensity is much higher than that of $\operatorname{AgBr} / \operatorname{Br}(1: 2)-\mathrm{GCN}(1: 3)$ and $\operatorname{AgBr} /$ $\operatorname{Br}(1: 4)-G C N(1: 3)$, but still lower than $\operatorname{AgBr} / \operatorname{GCN}(1: 3)$. Such PL quenching is possible due to the non-radiative transition.

Room temperature electron paramagnetic resonance (EPR) was used to investigate the electronic property of the asprepared catalysts. As shown in Fig. 6, GCN shows almost no EPR signal. After coupling with $\mathrm{AgBr}$, the sample also displays no EPR signal for $\operatorname{AgBr} / \operatorname{GCN}(1: 3)$. However, $\operatorname{AgBr} / \operatorname{Br}(1: 4)-$ GCN(1:3) shows one single Lorentzian line centering at a $g=$ 2.003 , being originated from unpaired electrons on $\pi$-conjugated $\mathrm{g}-\mathrm{C}_{3} \mathrm{~N}_{4}$ aromatic rings after $\mathrm{Br}$ doping. This is probably due to that the delocalization of the valance electron of $\mathrm{Br}$ in the $\mathrm{g}-\mathrm{C}_{3} \mathrm{~N}_{4}$ conjugation system can widen the band distribution, which improves the charge migration. ${ }^{15}$ This is consistent with the PL result.

Fig. 7 displays the photocatalytic $\mathrm{H}_{2} \mathrm{O}_{2}$ production ability over as-prepared catalysts. It is clearly seen that the $\mathrm{H}_{2} \mathrm{O}_{2}$ concentration of as-prepared catalyst increases with time for about $5 \mathrm{~h}$ when it reaches a constant level. This level corresponds to the steady-state where the rate of $\mathrm{H}_{2} \mathrm{O}_{2}$ production is equal to the rate of decomposition. ${ }^{32}$ In Fig. 7a, GCN and $\mathrm{AgBr}$ display the $\mathrm{H}_{2} \mathrm{O}_{2}$ concentration of 0.5 and $0.2 \mathrm{mmol} \mathrm{L}^{-1}$. In the case of as-prepared heterojunction catalyst, the $\mathrm{H}_{2} \mathrm{O}_{2}$ production ability promotes obviously. After $\mathrm{Br}$ doping, the photocatalytic performance of as-prepared samples further increase, as shown in Fig. 7b. This is due to that the introduction of heteroatoms into the $\pi$-conjugated $\mathrm{g}-\mathrm{C}_{3} \mathrm{~N}_{4}$ can accelerate the charge carriers transfer rate and thus restrain the recombination of electron and hole. $\operatorname{AgBr} / \operatorname{Br}(1: 4)-\operatorname{GCN}(1: 3)$ shows the highest $\mathrm{H}_{2} \mathrm{O}_{2}$ equilibrium concentration of $3.9 \mathrm{mmol} \mathrm{L}^{-1}$, which is 7.8 and 19.5 times higher than that of GCN and $\mathrm{AgBr}$. The excess $\mathrm{Br}$ doping causes the decreased $\mathrm{H}_{2} \mathrm{O}_{2}$ production ability of $\operatorname{AgBr} / \operatorname{Br}(1: 8)-G C N(1: 3)$. This is probably due to that the excess doping $\mathrm{Br}$ acts as recombination sites to accelerate the recombination of electrons and holes, which is consistent with PL result.

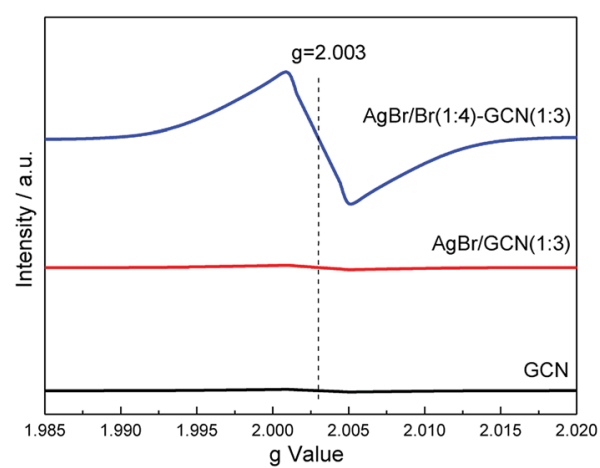

Fig. 6 EPR spectra of as-prepared $\mathrm{GCN}, \operatorname{AgBr} / \mathrm{GCN}(1: 3)$ and $\mathrm{AgBr} /$ $\operatorname{Br}(1: 4)-G C N(1: 3)$. 

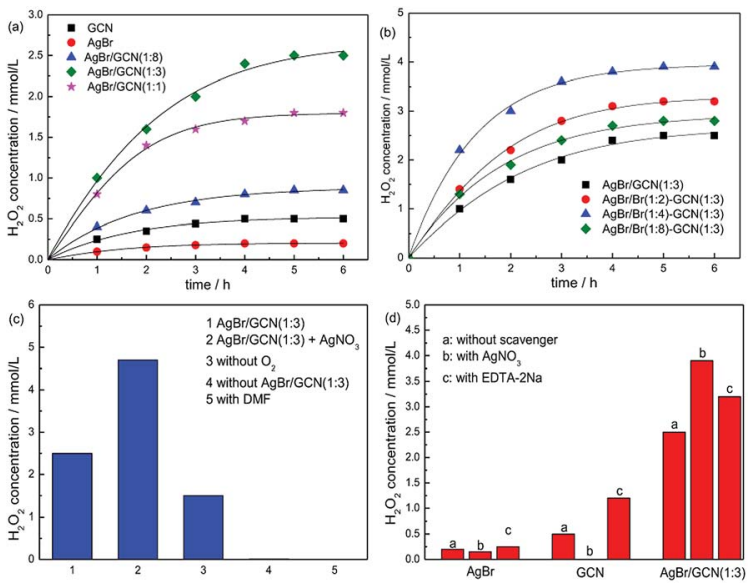

Fig. 7 The $\mathrm{H}_{2} \mathrm{O}_{2}$ production ability over as-prepared catalysts (a and b), the $\mathrm{H}_{2} \mathrm{O}_{2}$ production ability of $\mathrm{AgBr} / \mathrm{GCN}(1: 3)$ under different reaction conditions (c) and the influence of various scavengers on the $\mathrm{H}_{2} \mathrm{O}_{2}$ production ability over as-prepared catalysts (d).

Fig. 7c shows the $\mathrm{H}_{2} \mathrm{O}_{2}$ production ability of $\mathrm{AgBr} / \mathrm{GCN}(1: 3)$ under different reaction conditions. The addition of $\mathrm{AgNO}_{3}$ $\left(10 \mathrm{mmol} \mathrm{L}^{-1}\right)$ as an electron scavenger should suppress the $\mathrm{H}_{2} \mathrm{O}_{2}$ production ability. However, interestingly, the $\mathrm{H}_{2} \mathrm{O}_{2}$ production ability of $\mathrm{AgBr} / \mathrm{GCN}(1: 3)$ increases to $4.7 \mathrm{mmol} \mathrm{L}^{-1}$ when $\mathrm{AgNO}_{3}$ is added. Still $1.5 \mathrm{mmol} \mathrm{L} \mathrm{m}^{-1} \mathrm{H}_{2} \mathrm{O}_{2}$ is obtained in the absence of $\mathrm{O}_{2}$. These results indicate that $\mathrm{H}_{2} \mathrm{O}_{2}$ is not only produced by $\mathrm{O}_{2}$ reduction over $\operatorname{AgBr} / \mathrm{GCN}(1: 3)$. The detailed explanation is given below. The $\mathrm{H}_{2} \mathrm{O}_{2}$ concentration is trivial in the absence of photocatalyst, indicating that $\mathrm{H}_{2} \mathrm{O}_{2}$ is produced via a photocatalytic process. $\mathrm{No}_{2} \mathrm{O}_{2}$ is generated when using dimethylformamide (DMF, aprotic solvent) instead of water, confirming that $\mathrm{H}_{2} \mathrm{O}$ is necessary as the proton source for $\mathrm{H}_{2} \mathrm{O}_{2}$ production.

$$
\begin{gathered}
\mathrm{h}^{+}+\mathrm{OH}^{-} \rightarrow \cdot \mathrm{OH} \\
\cdot \mathrm{OH}+\cdot \mathrm{OH} \rightarrow \mathrm{H}_{2} \mathrm{O}_{2}
\end{gathered}
$$

Besides the $\mathrm{O}_{2}$ reduction to form $\mathrm{H}_{2} \mathrm{O}_{2}$, another channel to produce $\mathrm{H}_{2} \mathrm{O}_{2}$ is reported by Dong et al. ${ }^{33}$ It is reported that photogenerated holes can oxidize $\mathrm{OH}^{-}$to $\cdot \mathrm{OH}$ thermodynamically, as shown in reaction (3). Two $\cdot \mathrm{OH}$ can form $\mathrm{H}_{2} \mathrm{O}_{2}$ though combination with each other, as shown in reaction (4). In order to investigate the reaction mechanism of as-prepared heterojunction catalyst, the influence of various scavengers on the $\mathrm{H}_{2} \mathrm{O}_{2}$ production ability is carried out and shown in Fig. 7d. $\mathrm{AgNO}_{3}$ and EDTA-2Na are used as the electrons $\left(\mathrm{e}^{-}\right)$and hole $\left(\mathrm{h}^{+}\right)$scavenger, respectively. ${ }^{34}$ When $\mathrm{AgNO}_{3}$ is added to trap the electrons, $\mathrm{H}_{2} \mathrm{O}_{2}$ is still formed with the concentration of $0.15 \mathrm{mmol} \mathrm{L}^{-1}$ over $\mathrm{AgBr}$. It is known that the redox potential for $\cdot \mathrm{OH} / \mathrm{OH}^{-}$is $+1.99 \mathrm{~V}^{35}$ Whereas the $\mathrm{VB}$ of $\mathrm{AgBr}$ is $+2.15 \mathrm{~V}$. The VB holes in $\mathrm{AgBr}$ is positive enough to generate $\cdot \mathrm{OH}$. Therefore, $\mathrm{H}_{2} \mathrm{O}_{2}$ should be produced by reaction (4). When EDTA-2Na is added to trap the holes, although the utilization rate of electrons is promoted, the $\mathrm{H}_{2} \mathrm{O}_{2}$ equilibrium concentration is only increased to $0.45 \mathrm{mmol} \mathrm{L}^{-1}$ over AgBr. This is probably due to the poor reduction ability of $\mathrm{CB}$ electrons over $\mathrm{AgBr}$. In the case of GCN, the $\mathrm{CB}$ and VB positions are $-1.43 \mathrm{~V}$ and $+1.32 \mathrm{~V}$, respectively. Thus, when $\mathrm{AgNO}_{3}$ is added, no $\mathrm{H}_{2} \mathrm{O}_{2}$ is produced due to that the VB holes in $\mathrm{g}-\mathrm{C}_{3} \mathrm{~N}_{4}$ are not positive enough to generate $\cdot \mathrm{OH}$. Without any doubt, the $\mathrm{H}_{2} \mathrm{O}_{2}$ production ability of $\mathrm{g}-\mathrm{C}_{3} \mathrm{~N}_{4}$ is obviously promoted by adding EDTA-2Na to trap the holes.

In general, there are two typical working mechanisms for heterojunction catalyst, double charge transfer mechanism and $Z$-scheme mechanism, as shown in Fig. 8a. ${ }^{36-38}$ If $\mathrm{AgBr} /$ GCN(1:3) catalyst follows the double charge transfer mechanism, holes should be transferred to the VB of GCN. When CB electrons is trapped by $\mathrm{AgNO}_{3}$, VB holes in GCN are not positive enough to generate $\cdot \mathrm{OH}$. Thus $\mathrm{H}_{2} \mathrm{O}_{2}$ should be not produced. However, the $\mathrm{H}_{2} \mathrm{O}_{2}$ with the concentration of $3.9 \mathrm{mmol} \mathrm{L}^{-1}$ is formed over $\mathrm{AgBr} / \mathrm{GCN}(1: 3)$ when $\mathrm{AgNO}_{3}$ is added. Similarly, if $\mathrm{AgBr} / \mathrm{GCN}(1: 3)$ follows the double charge transfer mechanism, the electrons should be transferred to the CB of AgBr. The $\mathrm{H}_{2} \mathrm{O}_{2}$ production ability should be low by adding EDTA-2Na to trap the holes because of the poor reduction ability of $\mathrm{CB}$ electrons over AgBr. Whereas, the $\mathrm{H}_{2} \mathrm{O}_{2}$ equilibrium concentration over $\mathrm{AgBr} / \mathrm{GCN}(1: 3)$ is promoted to $3.2 \mathrm{mmol} \mathrm{L}^{-1}$ when EDTA-2Na is added. Based on the above results, it is deduced that not double charge transfer mechanism but $Z$-scheme mechanism with "two channel pathway" is proposed. Under visible light irradiation, the photogenerated electron-hole pairs are formed in both components. The electrons in the $\mathrm{CB}$ of AgBr combine with the holes in the VB of GCN at the interface of the heterojunction. Therefore, the holes tend to stay in the $\mathrm{VB}$ of $\mathrm{AgBr}$ and the electrons accumulate in the $\mathrm{CB}$ of GCN, leading to the enhanced separation rate of electron-hole pairs. The $\mathrm{CB}$ electrons in GCN can reduce $\mathrm{O}_{2}$ to form $\mathrm{H}_{2} \mathrm{O}_{2}$, as well as the VB holes in $\mathrm{AgBr}$ can oxidize $\mathrm{OH}^{-}$to form $\cdot \mathrm{OH}$, which subsequently react with each other to form $\mathrm{H}_{2} \mathrm{O}_{2}$. Such "two channel pathway" causes the remarkably promoted $\mathrm{H}_{2} \mathrm{O}_{2}$ production ability. When $\mathrm{AgNO}_{3}$ (or EDTA-2Na) is added to trap the electrons (or holes), the separation efficiency of catalyst is promoted, leading to the enhanced $\mathrm{H}_{2} \mathrm{O}_{2}$ production ability (Fig. 7d).

In order to prove the advance of this AgBr-Br-GCN heterojunction catalyst, $\mathrm{Ag}-\mathrm{AgBr}-\mathrm{CN}$ was prepared according to the previous work. ${ }^{18}$ Fig. $8 \mathrm{~b}$ compares the photocatalytic $\mathrm{H}_{2} \mathrm{O}_{2}$ production ability of $\mathrm{AgBr} / \mathrm{Br}(1: 4)-\mathrm{GCN}(1: 3)$ and $\mathrm{Ag}-\mathrm{AgBr}-\mathrm{CN}$. $\mathrm{Ag}-\mathrm{AgBr}-\mathrm{CN}$ shows the $\mathrm{H}_{2} \mathrm{O}_{2}$ concentration of $2.9 \mathrm{mmol} \mathrm{L}{ }^{-1}$,
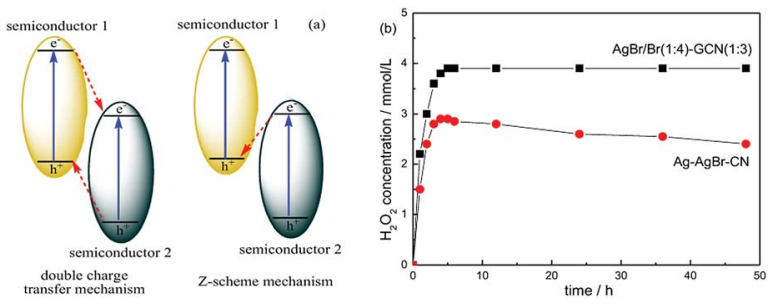

Fig. 8 The sketch map of double charge transfer mechanism and Zscheme mechanism over heterojunction catalyst (a) and the photocatalytic $\mathrm{H}_{2} \mathrm{O}_{2}$ production ability over $\operatorname{AgBr} / \operatorname{Br}(1: 4)-\mathrm{GCN}(1: 3)$ and $\mathrm{Ag}-\mathrm{AgBr}-\mathrm{CN}(\mathrm{b})$. 
much lower than that of $\operatorname{AgBr} / \operatorname{Br}(1: 4)-\mathrm{GCN}(1: 3)$. In addition, the $\mathrm{H}_{2} \mathrm{O}_{2}$ production ability for $\operatorname{AgBr} / \operatorname{Br}(1: 4)-\mathrm{GCN}(1: 3)$ keeps stable after $48 \mathrm{~h}$ reaction. Whereas, the activity for $\mathrm{Ag}-\mathrm{AgBr}-\mathrm{CN}$ decreases obviously with increasing the reaction time, hinting its poor photocatalytic stability. The element analysis and ICP results indicate that the content of each element in the $\mathrm{AgBr}$ / $\operatorname{Br}(1: 4)-\mathrm{GCN}(1: 3)$ remains almost unchanged before and after the reaction. However, for $\mathrm{Ag}-\mathrm{AgBr}-\mathrm{CN}$, the $\mathrm{Ag}$ content decreases obviously ( $\mathrm{Br}$ content does not change). This indicates the metal silver is not sturdy on the catalyst surface, which is probably lost during the reaction.

\section{Conclusions}

In this work, a two-component modified $\mathrm{AgBr}-\mathrm{Br}-\mathrm{g}-\mathrm{C}_{3} \mathrm{~N}_{4}$ composite catalyst with outstanding photocatalytic $\mathrm{H}_{2} \mathrm{O}_{2}$ production ability is synthesized. Modification with $\mathrm{Br}$ and $\mathrm{AgBr}$ does not change the structural property of $\mathrm{g}-\mathrm{C}_{3} \mathrm{~N}_{4}$ but decreases the band gap and increases the visible light absorption. The formation of heterojunction with $\mathrm{AgBr}$ and introduction of heteroatoms $\mathrm{Br}$ into the $\pi$-conjugated $\mathrm{g}-\mathrm{C}_{3} \mathrm{~N}_{4}$ can accelerate the charge carriers transfer rate and thus restrain the recombination of electron and hole. $\operatorname{AgBr} / \operatorname{Br}(1: 4)-\operatorname{GCN}(1: 3)$ shows the highest $\mathrm{H}_{2} \mathrm{O}_{2}$ equilibrium concentration of $3.9 \mathrm{mmol} \mathrm{L}^{-1}$, which is 7.8 and 19.5 times higher than that of GCN and $\mathrm{AgBr}$. According to " $Z$-scheme" mechanism, not only the $\mathrm{CB}$ electrons of GCN reduce $\mathrm{O}_{2}$ to form $\mathrm{H}_{2} \mathrm{O}_{2}$, but the VB holes in $\mathrm{AgBr}$ can oxidize $\mathrm{OH}^{-}$to form $\cdot \mathrm{OH}$, which subsequently react with each other to form $\mathrm{H}_{2} \mathrm{O}_{2}$. Such "two channel pathway" causes the remarkably promoted $\mathrm{H}_{2} \mathrm{O}_{2}$ production ability. In addition, compared with another two-component modified catalyst, $\mathrm{Ag}$ AgBr-g- $\mathrm{C}_{3} \mathrm{~N}_{4}, \quad \operatorname{AgBr} / \operatorname{Br}(1: 4)-\mathrm{GCN}(1: 3)$ displays the higher photocatalytic $\mathrm{H}_{2} \mathrm{O}_{2}$ production ability and stability.

\section{Conflicts of interest}

There are no conflicts to declare.

\section{Notes and references}

1 J. M. Campos-Martin, G. Blanco-Brieva and J. L. G. Fierro, Angew. Chem., Int. Ed., 2007, 45, 6962-6984.

2 C. Samanta, Appl. Catal., A, 2008, 350, 133-149.

3 S. Yamazaki, Z. Siroma, H. Senoh, T. Ioroi, N. Fujiwara and K. Yasuda, J. Power Sources, 2008, 178, 20-25.

4 S. A. M. Shaegh, N. T. Nguyen, S. M. M. Ehteshami and

S. H. Chan, Energy Environ. Sci., 2012, 5, 8225-8228.

5 S. Z. Hu, X. Chen, Q. Li, F. Y. Li, Z. P. Fan, H. Wang, Y. J. Wang, B. H. Zheng and G. Wu, Appl. Catal., B, 2017, 201, 58-69.

6 S. Z. Hu, X. Y. Qu, J. Bai, P. Li, Q. Li, F. Wang and L. J. Song, ACS Sustainable Chem. Eng., 2017, 5, 6863-6872.

7 S. N. Li, G. H. Dong, R. Hailili, L. P. Yang, Y. X. Li, F. Wang, Y. B. Zeng and C. Y. Wang, Appl. Catal., B, 2016, 190, 26-35. 8 Y. Feng, J. C. Shen, Q. F. Cai, H. Yang and Q. H. Shen, New J. Chem., 2015, 39, 1132-1138.
9 L. Liu, Y. H. Qi, J. Y. Yang, W. Q. Cui, X. G. Li and Z. S. Zhang, Appl. Surf. Sci., 2015, 358, 319-327.

10 T. T. Li, Y. M. He, H. J. Lin, J. Cai, L. Z. Dong, X. X. Wang, M. F. Luo, L. H. Zhao, X. D. Yi and W. Z. Weng, Appl. Catal., B, 2013, 138-139, 95-103.

11 Y. M. He, J. Cai, T. T. Li, Y. Wu, H. J. Lin, L. H. Zhao and M. F. Luo, Chem. Eng. J., 2013, 215-216, 721-730.

12 S. Y. Yang, W. Y. Zhou, C. Y. Ge, X. T. Liu, Y. P. Fang and Z. S. Li, RSC Adv., 2013, 3, 5631-5638.

13 Z. Feng, L. Zeng, Y. J. Chen, Y. Y. Ma, C. R. Zhao, R. S. Jin, Y. Lu, Y. Wu and Y. M. He, J. Mater. Res., 2017, 32, 36603668.

14 Z. Wan, G. K. Zhang, X. Y. Wu and S. Yin, Appl. Catal., B, 2017, 207, 17-26.

15 Z. A. Lan, G. G. Zhang and X. C. Wang, Appl. Catal., B, 2016, 192, 116-125.

16 Y. Y. Bu, Z. Y. Chen and W. B. Li, Appl. Catal., B, 2014, 144, 622-630.

17 Y. L. Wang, M. Z. Xia, K. B. Li, X. L. Shen, T. Muhanmood and F. Y. Wang, Phys. Chem. Chem. Phys., 2016, 18, 2725727264.

18 D. M. Chen, Z. H. Wang, Y. Du, G. L. Yang, T. Z. Ren and H. Ding, Catal. Today, 2015, 258, 41-48.

19 Y. Wang, Y. Di, M. Antonietti, H. R. Li, X. F. Chen and X. C. Wang, Chem. Mater., 2010, 22, 5119-5121.

20 Y. Ding, W. Zhao, H. Hu and B. C. Ma, Green Chem., 2008, 10, 910-913.

21 M. Saha, M. Das, R. Nasani, I. Choudhuri, M. Yousufuddin, H. P. Nayek, M. M. Shaikh, B. Pathak and S. Mukhopadhyay, Dalton Trans., 2015, 44, 20154-20167.

22 X. C. Wang, K. Maeda, A. Thomas, K. Takanabe, G. Xin, K. Domen and M. Antonietti, Nat. Mater., 2009, 8, 76-80.

23 B. Oregan and M. Gratzel, Nature, 1991, 353, 737-740.

24 B. Chai, T. Y. Peng, J. Mao, K. Li and L. Zan, Phys. Chem. Chem. Phys., 2012, 14, 16745-16752.

25 L. Ge and C. Han, Appl. Catal., B, 2012, 117/118, 268-274.

26 W. Lei, D. Portehault, R. Dimova and M. Antoniettit, J. Am. Chem. Soc., 2011, 133, 7121-7127.

27 Z. X. Ding, X. F. Chen, M. Antonietti and X. C. Wang, Chemsuschem, 2011, 4, 274-281.

28 Y. W. Zhang, J. H. Liu, G. Wu and W. Chen, Nanoscale, 2012, 4, 5300-5303.

29 J. Jiang, H. Li and L. Z. Zhang, Chem.-Eur. J., 2012, 18, 63606369.

30 S. L. Lin, L. Liu, J. S. Hu, Y. H. Liang and W. Q. Cui, Appl. Surf. Sci., 2015, 324, 20-29.

31 A. Basagni, L. Ferrighi, M. Cattelan, L. Nicolas, K. Handrup, L. Vaghi, A. Papagni, F. Sedona, C. D. Valentin, S. Agnoli and M. Sambi, Chem. Commun., 2015, 51, 12593-12596.

32 M. Teranishi, S. Naya and H. Tada, J. Am. Chem. Soc., 2010, 132, 7850-7851.

33 L. P. Yang, G. H. Dong, D. L. Jacobs, Y. H. Wang, L. Zang and C. Y. Wang, J. Catal., 2017, 352, 274-281.

34 S. Q. Zhang, Y. X. Yang, Y. N. Guo, W. Guo, M. Wang, Y. H. Guo and M. X. Huo, J. Hazard. Mater., 2013, 261, 235-245. 
35 G. Liu, P. Niu, L. C. Yin and H. M. Cheng, J. Am. Chem. Soc., 2012, 134, 9070-9073.

36 K. Kondo, N. Murakami, C. Ye, T. Tsubota and T. Ohno, Appl. Catal., B, 2013, 142/143, 362-367.
37 Y. M. He, L. H. Zhang, B. T. Teng and M. H. Fan, Environ. Sci. Technol., 2015, 49, 649-656.

38 Y. M. He, L. H. Zhang, M. H. Fan, X. X. Wang, M. L. Walbridge, Q. Y. Nong, Y. Wu and L. H. Zhao, Sol. Energy Mater. Sol. Cells, 2015, 137, 175-184. 